\title{
ОСОБЕННОСТИ И ФАКТОРЫ РАЗВИТИЯ ИНФОРМАЦИОННО-КОММУНИКАЦИОННОГО СЕКТОРА
}

\author{
(С) 2021 Орлов И.Ю. \\ кандидат экономических наук, докторант \\ Казанский (Приволжский) федеральный университет, Россия, Казань \\ E-mail:snf079@yandex.ru
}

(c) 2021 Ибрагимов Л.г.

кандидат экономических наук, доцент

Казанский филиал Российского государственного университета правосудия, Россия, Казань

E-mail: Farid.Abdoulganiev@ksu.ru

В настоящее время наблюдаются существенные достижения глобального информационного общества в области развития сектора информационно-коммуникационных технологий, являющегося ключевым инструментом экономического развития на основе видов экономической деятельности, связанных с производством предназначенной или способствующей выполнению функций обработки, передачи и отображения информации на основе электронных средств продукции, включая передачу и отображение информации продукции.

В работе представлена оценка возможностей развития отрасли информационно-коммуникационных технологий Российской Федерации. Выявлено, что наибольшее положительное влияние оказывают факторы формирования благоприятной институциональной среды и проникновение технологий во все сферы жизнедеятельности (свыше 80\%). Необходимо отметить, что перспективы развития отрасли информационных технологий напрямую коррелируют с мерами государственной поддержки секторов экономики страны. По итогам 2020 года выявлен значительный рост объема услуг, связанных с передачей данных, доступом к сети Интернет на основе проводной и подвижной связи, составивший от 300 до 600\%. При этом отмечено двукратное сокращение спроса на проводную телефонную связь и пятикратное сокращение на услуги IP-телефонии. в настоящее время наибольший спрос отмечен для оборудования, обеспечивающего организацию удаленной работы, такого, как серверное и телекоммуникационное оборудование, направленное на масштабирование систем обеспечения удаленного доступа: терминального доступа, инфраструктуры виртуальных рабочих столов, оборудования операторов контакт-центров и оснащения центров обработки вызовов, ноутбуков, неттопов, персональных компьютеров, мониторов, планшетов, мобильных роутеров.

Ключевые слова: информационно-коммуникационные технологии, отрасль информационных технологий, деятельность в сфере телекоммуникаций, сегмент производства ИКТ, развитие ИКТ.

Внедрение и активизация современных информационно-коммуникационных технологий способствует реализации деятельности в различных областях общественной жизни, обусловливая положительную динамику стратегической позиции Российской Федерации в долгосрочной перспективе за счет стимулирования инновационной деятельности, реструктуризации социально-экономического развития, а также повышения производительности и совершенствования труда [1].

Структура сектора информационно-коммуникационных технологий Российской Федерации включает в себя следующие сегменты:

- -производство ИКТ;

- оптовая торговля товарами, связанными с ИКТ;
- деятельность в сфере телекоммуникаций;

- отрасль информационных технологий;

- прочие ИКТ-услуги.

Исследование динамики развития сектора информационно-коммуникационных технологий Российской Федерации продемонстрировало позитивную тенденцию прироста по показателю индекса физического объема валовой добавленной стоимости за период 2012-2020 гг. за исключением 2016 года, когда в анализируемом секторе наблюдалось значительное падение на 1,7\% от данных предыдущего года. При этом необходимо отметить опережающий рост сектора информационно-коммуникационных технологий Российской Федерации по сравнению с динамикой валового внутреннего продукта за исследуемый период [3], что представлено на рис. 1. 
Представленная динамика развития сектора информационно-коммуникационных технологий Российской Федерации за 2012-2020 гг. в целом соответствовала общемировой динамике развития аналогичного сектора до 2020 года, однако в период пандемии COVID-19 на мировом рынке в связи с вводимыми в странах ограничениями наблюдается снижение спроса на товары и услуги [8]. В соответствие с оценками Global Research and Advisory Company Gartner, по итогам 2020 г. прогнозировалось падение мирового рынка информационно-коммуникационных технологий на 8\% до уровня 2015-2016 гг.

Однако в соответствие с проведенными ис- следованиями рынка информационно-коммуникационных технологий в Российской Федерации в 2020 году данный пессимистический прогноз не соответствует реальной ситуации, так как сектор информационно-коммуникационных технологий занимает пятое место среди лидирующих секторов по показателю динамики валовой добавленной стоимости, что представлено на рис. 2.

По результатам деятельности в 2020 году лидирующими отраслями являются финансовый сектор (+7,9\%), производство мебели $(+7,6 \%)$, производство лекарственных средств (+22,2\%), производство химических веществ

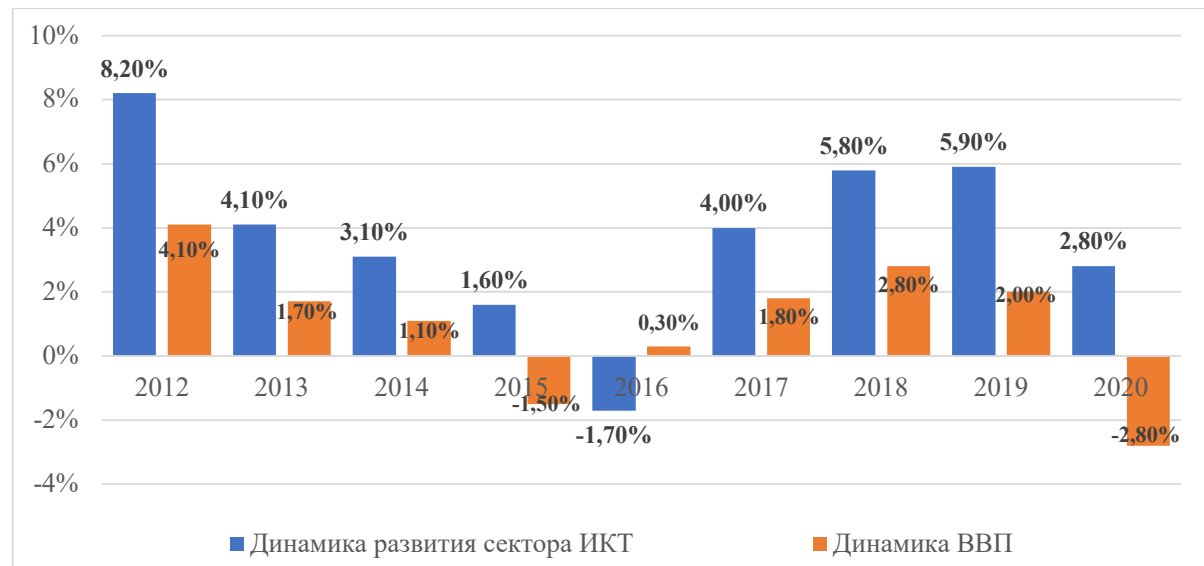

Puc. 1. Сравнительная динамика развития сектора информационно-коммуникационных технологий и валового внутреннего продукта Российской Федерации за 2012-2020 гг.

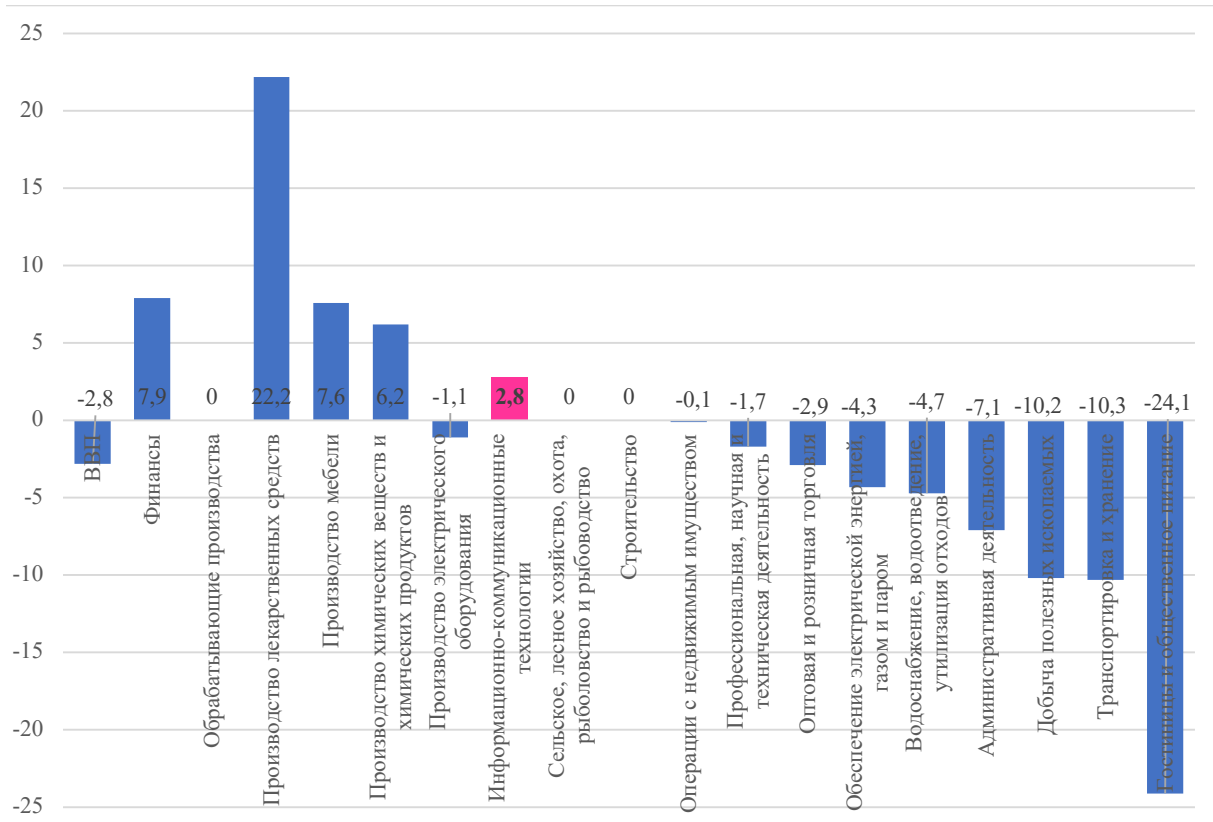

Puc. 2. Динамика индекса физического объема валовой добавленной стоимости по видам экономической деятельности Российской Федерации в 2020 году по отношению к 2019 году (в \%). 
и химических продуктов $(+6,2 \%)$ и сектор информационно-коммуникационных технологий (+2,8\%). При общем падении величины валового внутреннего продукта $(-2,8 \%)$ по сравнению с данными за 2019 год доля сектора информационно-коммуникационных технологий в экономике Российской Федерации демонстрирует достижение собственного максимума, равного 3,1\% ВВП (для сравнения: в 2019 г. данная величина составляла 2,9\%).

В структуре сектора информационно-коммуникационных технологий Российской Федерации в 2020 году наблюдается следующая динамика его сегментов (рис. 3.)

Анализ показал, что положительную динамику сектора информационно-коммуникационных технологий Российской Федерации в 2020 году обеспечили отрасль информационных технологий $(+12,7 \%)$, сектор производства информационно-коммуникационных технологий $(+4,1 \%)$ и сектор оптовой торговли товарами, связанными с информационно-коммуникационными технологиями (+30,9\%). При этом в деятельности секторов в сфере телекоммуникаций и прочих ИКТ-услуг наблюдается снижение активности на 1,6\% и 31,3\% соответственно.

Указанная динамика обусловливается ограничениями, связанными с пандемией новой коронавирусной инфекции COVID-19, в соответствии с которыми за первый квартал 2020 года отмечалось снижение объемов продаж ИКТ-услуг $(-8,3 \%)$, наблюдаемого только на внутреннем рынке, так как экспорт услуг информацион- но-коммуникационных технологий увеличился на 24,8\%. Однако, начиная со второго квартала 2020 года, отмечался существенный рост данного вида услуг, связанный с ограничением деятельности в режиме офф-лайн и активизацией дистанционного функционирования, что обусловило наращивание объемов продаж (за период январь-июнь прирост составил $+9,9 \%$, а за период январь-сентябрь $+21,8 \%)$ на внутреннем рынке, при этом экспорт услуг данного сегмента при сохраняющейся позитивной динамике $(+112,7 \%)$ продемонстрировал отставание от темпов прироста импорта (+127,1\%) за период январь-сентябрь 2020 г. по отношению к аналогичному периоду 2019 года. Кроме того, сальдо данного вида услуг оставалось положительным за указанный период и составило +688 млн. долл. США, несмотря на сокращение его объема на $23,9 \%$.

Сегмент деятельности в сфере телекоммуникаций в январе-сентябре 2020 года демонстрирует умеренно положительную динамику объема реализованных услуг (прирост от 2 до 5\%), однако за период октябрь-декабрь 2020 года отмечается среднемесячный прирост в размере 8,9\%. Таким образом, по итогам 2020 года выявлен значительный рост объема услуг, связанных с передачей данных, доступом к сети Интернет на основе проводной и подвижной связи, составивший от 300 до 600\%. При этом отмечено двукратное сокращение спроса на проводную телефонную связь и пятикратное сокращение на услуги IP-телефонии.

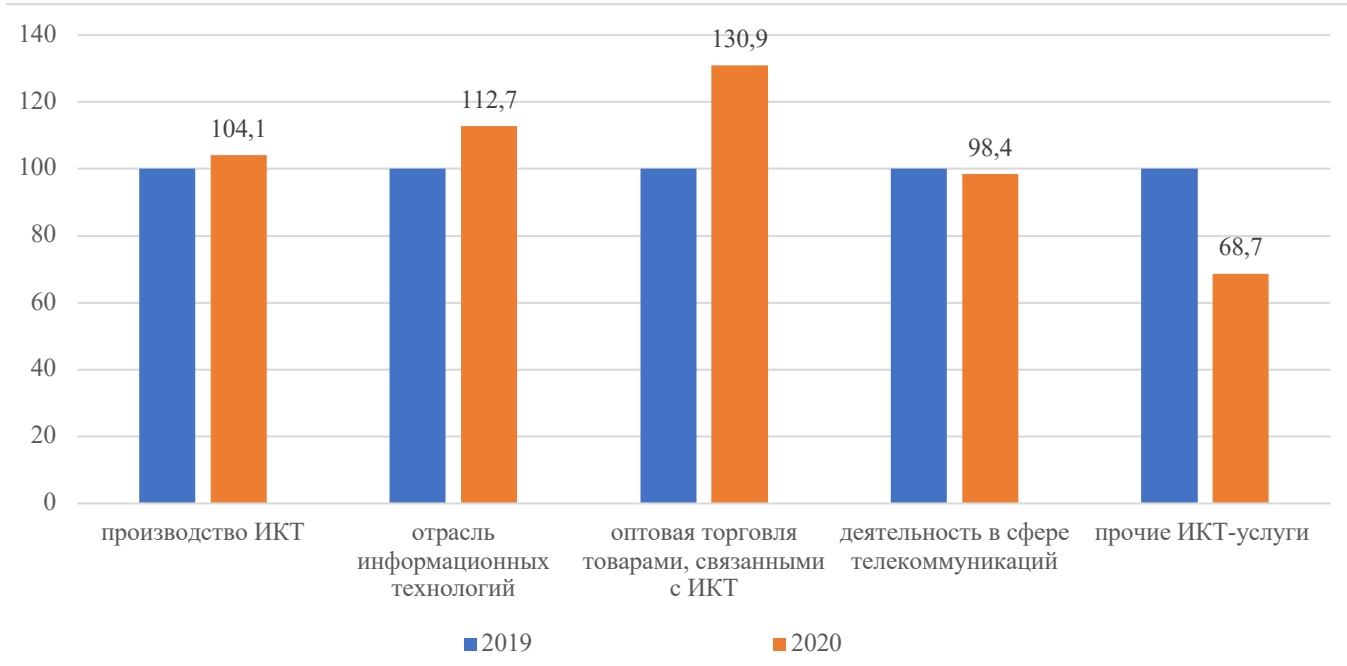

Puc. 3. Динамика индекса физического объема валовой добавленной стоимости сектора информационно-коммуникационных технологий Российской Федерации по видам экономической деятельности в 2020 году по сравнению с 2019 годом (в\%) 
Значительный прирост в сегменте оптовой торговли товарами, связанными с ИКТ $(+30,9 \%)$ обусловлен высоким спросом на данные товары, особенно на персональные компьютеры, обусловивший наращивание оборота организаций данного сегмента, специализирующихся на продаже компьютеров, периферийных устройств к ним и программного обеспечения, в 1,8 раза.

В сегменте производства информационно-коммуникационных технологий за период январь-сентябрь 2020 года наблюдалось снижение по сравнению с аналогичным периодом 2019 года $(-3,83 \%)$, скомпенсированное дальнейшим наращиванием объемов производства в течение октября-декабря 2020 года $(+7,93 \%)$, что позволило обеспечить положительную динамику развития данного сегмента отрасли за 2020 год в целом.

Исследование инвестиционной активности в отношении сегментов сектора информационно-коммуникационных технологий продемонстрировало положительную динамику для сегментов производства информационно-коммуникационных технологий $(+14,9 \%)$, отрасли информационных технологий $(+12,8 \%)$ и оптовой торговли товарами, связанными с ИКТ (+3,9\%). При этом необходимо отметить, что в целом по отрасли информационно-коммуникационных технологий за 2020 год отмечено сокращение объема инвестиций в основной капитал на 2,9\% по сравнению с аналогичны- ми данными за 2019 год, что обусловливается значительным сокращением инвестиционной активности в сегментах деятельности в сфере телекоммуникаций $(-7,9 \%)$ и прочих ИКТ-услуг (-26,8\%). Наглядно данная динамика представлена на рис. 4.

Таким образом, можно констатировать факт достаточной устойчивости сектора информационно-коммуникационных технологий Российской Федерации, продемонстрированной в 2020 году в сложной экономической ситуации, и обусловленной значительным ростом востребованности информационно-коммуникационных товаров и услуг среди всех экономических субъектов [2].

Исследование динамики объема рынка услуг в сфере информационных технологий, включающего в себя внедренческий консалтинг, установку и поддержку оборудования и программного обеспечения, а также системную интеграцию и прочие услуги поддержки систем, наглядно представлено на рис. 5. В соответствии с ним можно отметить достаточно стабильную положительную динамику объема рынка услуг, предоставляемых в сфере информационных технологий, выраженного в рублевом эквиваленте, за исключением 2009 года, демонстрировавшего спад на $12,1 \%$. Но это не является объективным показателем развития данного рынка, в отличие от динамики объема рынка услуг, предоставляемых в сфере информационных

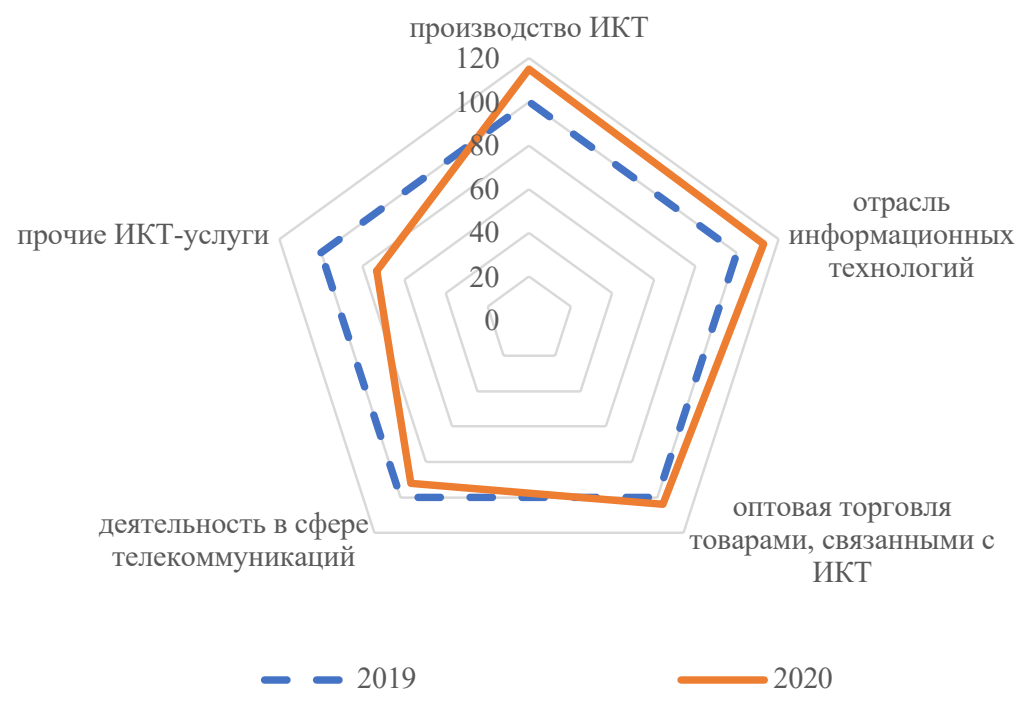

Puc. 4. Динамика индекса физического объема инвестиций в основной капитал сектора информационно-коммуникационных технологий Российской Федерации за период 2019-2020 гг. по сегментам отрасли. 
технологий, выраженного в долларовом эквиваленте, отражающего достаточно нестабильную динамику, однако объективированную реалистичностью стоимости данных услуг и, соответственно, их востребованностью [10]. Во втором случае значительные «провалы» данного рынка зафиксированы не только в 2009 году, но и в период 2013-2016 гг. Однако, в целом направленность развития оценивается как позитивная, при этом прирост объема российского рынка услуг, предоставляемых в сфере информационных технологий, в 2020 году составил $14,2 \%$ по сравнению с данными за 2019 год, что обусловливается положительным влиянием мероприятий, связанных с пандемией новой коронавирусной инфекции COVID-19, выступив «катализатором» динамики за счет активизации цифровой трансформации в различных экономических отраслях.

Необходимо отметить, что указанные мероприятия оказали и негативное влияние, обусловив сокращение текущих расходов и объема инвестиций на информационные технологии как стандартного способа реагирования на экономический кризис, в соответствии с чем часть информационных услуг, таких, к примеру, как услуги, предоставляемые в рамках офисной инфраструктуры, оказались невостребованными [9]. Кроме того, произошло перераспределение запросов на рынке услуг, предоставляемых в сфере информационных технологий, за счет сокращения числа существующих крупных проектов и одновременно возникшего множества новых заказчиков.

Актуализировалось направление услуг для удаленной работы, заключающихся в удаленном мониторинге инфраструктуры и оборудования в сфере информационных технологий, поддержке пользователей, обеспечении информационной безопасности, формировании и переносе решений и баз данных в сфере информационных технологий в «облачный» формат, предоставлении инфраструктуры и программного обеспечения в сфере информационных технологий для организации работы распределенных команд и пр [6]. Также необходимо отметить значительное увеличение количества запросов на предоставляемые услуги со стороны сферы образования в связи с массовостью перевода на дистанционное обучение, обусловившее необходимость значительного объема информационных ресурсов для функционирования инфраструктуры.

Таким образом, в настоящее время наибольший спрос отмечен для оборудования, обеспечивающего организацию удаленной работы, такого, как серверное и телекоммуникационное оборудование, направленное на масштабирование систем обеспечения удаленного доступа: терминального доступа, инфраструктуры виртуальных рабочих столов, оборудования операторов контакт-центров и оснащения центров обработки вызовов, ноутбуков, неттопов, персональных компьютеров, мониторов, планшетов, мобильных роутеров.

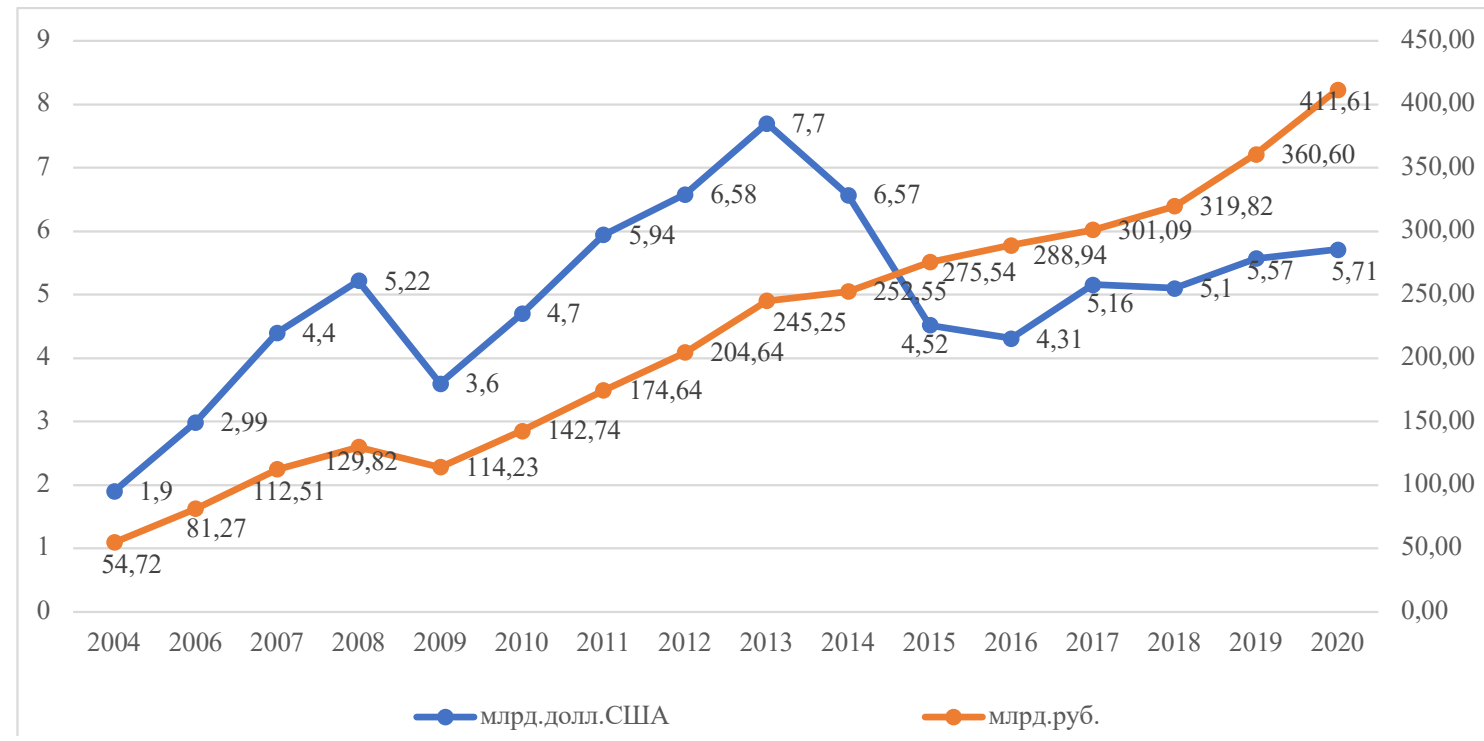

Puc. 5. Динамика объема рынка услуг, предоставляемых в сфере информационных технологий, по Российской Федерации, 2004-2020 гг. 
В соответствии с открытыми статистическими данными, для Российской Федерации в 2019-2020 годах определен профицит баланса внешней торговли услугами относительно телекоммуникационных, компьютерных и информационных услуг в размере 0,18 млрд. долл. США, что отражает прирост экспорта данного вида услуг $(+4,3 \%$ в 2020 году по сравнению с аналогичным периодом за 2019 год), хотя и несколько снижающийся в сравнении с 10\%-ным приростом в 2017 году.

Отмечается существенное увеличение удельного веса услуг сферы информационных технологий в объеме совокупного экспорта Российской Федерации с 0,94\% в 2019 году до 1,3\% в 2020 году с соответствующим увеличением дохода от данных услуг на $13,5 \%$ в долларовом выражении, что обусловливается резким сокращением расходов на зарубежные маркетинговые мероприятия в связи с ограничениями, связанными с пандемией новой коронавирусной инфекции COVID-19.

Структуризация и динамика внешнеторгового оборота услуг сферы информационных технологий Российской Федерации в течение 2010-2020 годов представлена на рис. 6.

Необходимо отметить положительные тенденции в развитии экспорта услуг сферы информационных технологий Российской Федерации с 2017 года, превышающего импорт данного вида услуг на $17 \%$ в 2018 году, на 25\% в 2019 году и на $41,6 \%$ в 2020 году.

Указанная динамика может быть объяснена тем, что на фоне наращивания спроса на товары и услуги, предоставляемые в сфере информационных технологий, 29.06.2020 года Соединенными Штатами Америки в отношение Российской Федерации, а также Китая и Венесуэлы введены экспортные ограничения в отношении «чувствительных технологий», включающие в себя санкции на технологические товары, потенциально используемые для создания военной продукции (полупроводниковое оборудование, датчики и пр.), а также ужесточение контроля и эскалация требований к наличию лицензий на поставляемый товар (телекоммуникационное оборудование, персональные компьютеры, полупроводники и пр.), что обусловлено переводом Соединенными Штатами Америки Российской Федерации в группу стран «D», неблагонадежную в отношении разработки и содействию развития ядерных и ракетных технологий.

Указанные ограничения могут способствовать производству импортозамещающей продукции для данной отрасли, однако большинство данной продукции и услуг непосредственно зависят от импортных комплектующих товаров, производимых в Соединенных Штатах Америки или зависящих от их лицензий. Необходимо также отметить более высокую стоимость оте-

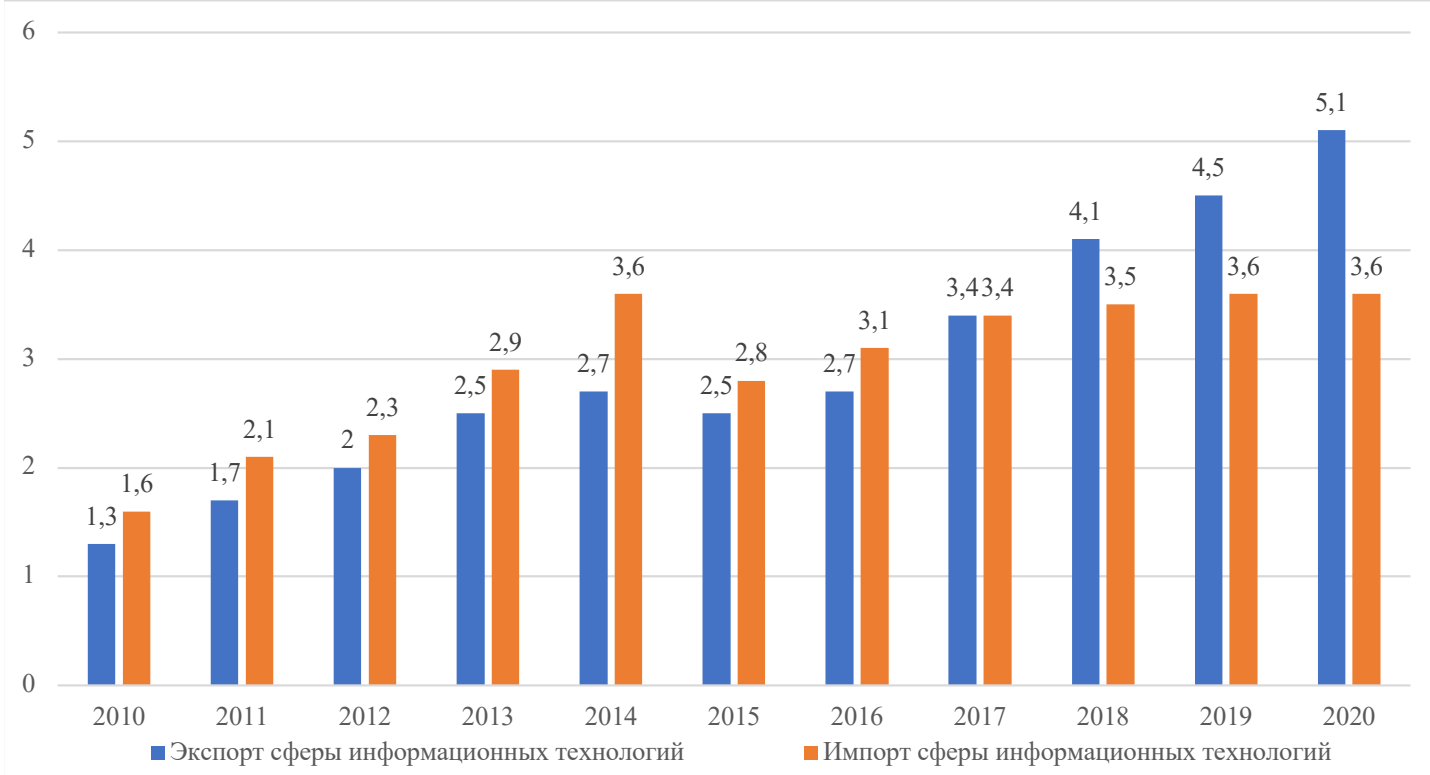

Puc. 6. Структура внешнеторгового оборота услуг сферы информационных технологий Российской Федерации, 2010-2020 гг., млрд. долл. США 
чественного оборудования по сравнению с импортным, что в существующих экономических условиях может представлять собой весьма значимый фактор для потребителей [7].

Оценка возможностей развития отрасли информационно-коммуникационных технологий Российской Федерации показала, что наибольшее положительное влияние оказывают факторы формирования благоприятной институциональной среды и проникновение технологий во все сферы жизнедеятельности (свыше 80\%). Спорной является возможность распространения российского проприетарного программного обеспечения по причине разработки модели «open source», что обусловливает и относительную неустойчивость такой возможности развития, как расширение международного сотрудничества на рынке информационных технологий. Указанные возможности способствуют наращиванию конкурентоспособности как отрасли в целом, так и специалистов в частности.

Необходимо отметить, что перспективы развития отрасли информационных технологий напрямую коррелируют с мерами государственной поддержки секторов экономики страны. Сокращающиеся с 2020 года инвестиционные вложения в отрасль информационно-коммуни- кационных технологий обусловливают снижение как внутренней, так и внешней конкурентоспособности соответствующих товаров и услуг Российской Федерации [5]. При этом внедрение мер налогового стимулирования, по нашему мнению, обусловят восстановление докризисного уровня отрасли информационно-коммуникационных технологий и будут способствовать ее дальнейшему ускоренному росту, а также наращиванию цифрового и информационного социально-экономического развития Российской Федерации. Таким образом, указанные меры государственной поддержки в качестве основного катализатора увеличения добавленной стоимости отрасли информационно-коммуникационных технологий потенцируют экспорт услуг с соответствующим увеличением его удельного веса в отраслевой валовой добавленной стоимости, при этом реализуется концепция импортозамещения для продукции данной отрасли, что обусловит опережающую динамику развития отрасли информационно-коммуникационных технологий по сравнению с валовым внутренним продуктом, а также активизирует цифровую трансформацию в других экономических отраслях Российской Федерации.

\section{Библиографический список}

1. Кефели И. Ф., Мальмберг С.А. Информационный потенциал государства как основа информационного суверенитета// Управленческое консультирование. 2019. № 1. 2019. С. 29-39.

2. Сычанина С.Н., Шичиях Р.А. Программно-целевое управление: генезис и тенденции развития// Научный вестник Южного института менеджмента. 2013. № 4. С. 37-42. С. 41.

3. Таюрская И.С. Оценка информационного потенциала промышленности региона// Вестник факультета управления Санкт-Петербургского государственного экономического университета. Выпуск № 1 . Апрель 2017. C. 315-319.

4. Фахрутдинова Е.В. Диалектика потребностей человека// Экономические науки. 2009. № 57. С. 43-47.

5. Хабиб М.Д., Теплякова М.Ю., Краснов Е.В. Состояние финансирования научных исследований в Российской Федерации на современном этапе//Вестник университета. 2019. № 5. С. 151-158.

6. Adamides E., Karacapilidis $N$. Information technology for supporting the development and maintenance of open innovation capabilities // Journal of Innovation and Knowledge, 2020, 5 (1), pp. 29-38.

7. Adam I.O. ICT development, e-government development, and economic development: Does institutional quality matter? // Information Technologies and International Development, 2020, (16), pp. 1-19.

8. Kozłowski M., Brzozowska-Rup K., Piotrowska-Piątek, A. Information and Communication Technologies in food and accommodation sector in EU countries: Sticker or challenge for tourism development? // Technological Forecasting and Social Change, 2021, 171, 120941

9. Sinkovics R. R., Sinkovics, N. The Internet and international marketing - from trigger technology to platforms and new markets // International Marketing Review, 2020, 37 (3), pp. 437-446

10. Stone M., Aravopoulou E., Stott, R.,...Foss, B., Machtynger, L. The evolution of business models of information and communication technology suppliers // Bottom Line, 2021, 34 (1), pp. 1-19.

11. Fakhrutdinova E.V., Kolesnikova J.S., Fakhrutdinov R.M., Yagudin R.H. Shadow economy in Russia// Mediterranean Journal of Social Sciences. 2015. T. 6. № 1 S3. C. 67-72.

12. Fakhrutdinova E., Severyanov O., Shigabutdinov A., Fakhrutdinov R. The Crisis of 1998 in Russia: political intervention and its implication//Life Science Journal. 2014. T. 11. № 6s. C. 442-447. 